\title{
Knowledge and Acceptance of HIV Counselling And Testing (HCT) among Non-Teaching Staff of A Nigerian Private University
}

\author{
${ }^{1}$ Nwozichi C.U RN, RM, RPHN, MScN (in view) And ${ }^{1}$ Farotimi A.A. RN, Ph.D \\ ${ }^{1}$ School Of Nursing, Babcock University, Ogun State, P.M.B. 21244 Ikeja Lagos, Nigeria
}

\begin{abstract}
:
INTRODUCTION: HIV counselling and testing (HCT) is a very significant strategy used in the prevention, treatment and control of HIV/AIDS. Nigeria is one of the countries with highest rate of HIV/AIDS prevalence. Despite the current prevalence of about 5\%, very few Nigerian know their HIV status and HCT acceptance is very low even among the at-risk individuals. The broad objective of this study was to assess the level of knowledge and acceptance of HCT among non-teaching staff of a private university in Nigeria.

MATERIALS AND METHODS: A descriptive quantitative research design was adopted and a total of 126 participants were selected using a convenient non probability sampling technique. Tool for data collection was a self-structured questionnaire which was pretested and Spearman Brown's formula was used to determine the reliability of the tool which yielded a result of 0.97 meaning that the tool was reliable. Data collected were analyzed using SPSS to present the descriptive statistics of demographic variables. A chi-square test was used to measure the association between selected variables.

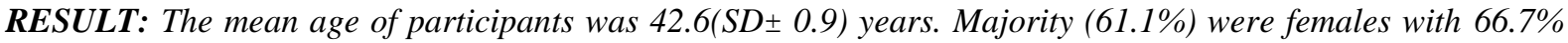
being married. Majority of participants (57.1 and 70.6\%) were knowledgeable and had acceptance of HCT respectively. Chi-square test shows a significant association between knowledge and acceptance of HCT among participants at $\chi^{2}$ Of 23.038 and $p$-value $<0.001$. Findings also revealed a strong association between gender, and marital status with acceptance of HCT with $p$-value $<0.05$ considered as significant.

CONCLUSION: The findings reveal that lack of knowledge regarding HCT is a major factor affecting its uptake and suggests that serious efforts should be made to increase awareness of HCT among individual. Confidentiality should be assured and maintained to reduce fear of stigma and discrimination. Based on the findings of this study, it is therefore recommended that nurses and other health professionals have a very vital role to play in disseminating the information regarding HCT. Information should be conveyed to everybody through mass media and public education so that individuals can really have the knowledge about the importance of HCT and the role it plays in the prevention, treatment and control of HIV/AIDS.
\end{abstract}

Key Words: Acceptance, HIV/AIDS, HIV Counseling and Testing, . Knowledge, Staff,

\section{Introduction}

HIV/AIDS has been identified as a major health concern all over the world. ${ }^{[1]}$. Nigeria has the second largest number of new cases reported each year and about $3.7 \%$ of its population are living with HIV/AIDS ${ }^{[2][3]}$. HIV epidemic in Nigeria is quite complex leading to the death of approximately 210,000 people in $2011^{[2]}$.

Being an epidemic, many countries have been making serious efforts to slow the spread of HIV infection and also reduce the burden on infected individuals ${ }^{[4]}$. Initially, Nigeria responded to the epidemic with denial and little action ${ }^{[5][6]}$ and the Nigerian political leadership latter took more proactive approaches to HIV/AIDS control ${ }^{[8]}$.

HIV counselling and testing (HCT) has been identified as a major component of HIV/AIDS prevention, care and control. HCT is a cost-effective strategy by which individuals undergo counselling enabling them to make informed choice about being tested for $\mathrm{HIV}^{[3]}$. HCT helps to reduce the risky behaviors among members of the community. The decision to get tested must be entirely the choice of the individual and he or she must be ensured that the process will be confidential. ${ }^{[4]}$.

HCT helps to facilitate behavioral changes around both preventing HIV as well as getting quick access to available support for those who test positive. It reduces the rate of indulgences into risky behaviors such as unprotected sex thus reducing the incidence of HIV and other sexually transmitted infections.

The uptake of HCT in Nigeria has remained lower than expected based on the incidence and prevalent rates $^{[9]}$. Distance to HCT facilities ${ }^{[4][10][12]}$, lack of knowledge regarding the importance of HCT $^{[13]}$ and stigmatization has been identified as major factors affecting the uptake of HCT. HCT is considered a pivotal service and a very vital entry point in the management of HIV/AIDS; providing a continuum for HIV prevention, care, treatment and support services. 
HCT uptake among individuals especially the at-risk groups such as sex workers, injection drug users, heterosexuals and homosexuals, must increase if Nigeria is to see a decline in the currently high levels of HIV prevalence.

In a cross-sectional study conducted to examine the factors associated with HCT behaviors among 393 Nigerian University students of Obafemi Awolowo University, Ile-Ife, only 30\% of the participants reported that they had been tested for HIV and only $14 \%$ of the participants who have never been tested indicated interest. $^{[12]}$. This reveals that many individuals have never been tested for HIV. Similarly, a study conducted to examine the prevalence and associated factors of intention to participate in HIV voluntary counseling and testing for the first time among men who have sex with men in Hong Kong, China, revealed that 245 out of 577 men who have sex with men have never participated in HCT among whom only $12.7 \%$ indicated intention to do so in the next six months ${ }^{[20]}$. This is an indication that many, even the at-risk group are yet to accept HCT despite the identified benefits.

Knowledge of HCT is a very important factor affecting the rate of uptake of this important service.

\section{Materials And Methods}

This study was conducted using a descriptive quantitative study design. A total of 126 participants were selected for this study with the use of convenient non probability sampling technique. Tool for data collection was a self- administered questionnaire which comprised of three sections. Section A related to demographic variables of participants, Section B on participants knowledge regarding HCT and Section C on acceptance of HCT among participants. The reliability of the questionnaire was ensured through a pilot study and Spearman Brown's formula was used to measure the reliability. Data collected were coded and analyzed with statistical package for social sciences (SPSS) 19 software. Descriptive statistics were used to give a clear view of the demographic variables. The knowledge and acceptance score of participants were computed to find the mean upon which decisions regarding participants knowledge and acceptance of HCT was made. Participants whose knowledge and acceptance scores were equal to or above the mean score were classified as being knowledgeable and having the acceptance of HCT respectively while those whose knowledge and acceptance scores were below average were considered not knowledgeable and do not have acceptance of HCT. The association between the knowledge and acceptance of HCT with demographic variables of participants were worked out and measured using chi-square. A p-value $<0.05$ was considered as significant in all circumstances.

\section{Demographic variables of participants:}

\section{Results}

Table 1 shows the demographic variables of participants. The number of participants that completed the questionnaire were 126 subjects among whom 77(61.1\%) were females and 49(38.9) were males. The mean age of the participants was 42.6 (SD \pm 0.9 ) years. Majority of the participants 62(49.2\%), $118(93.7 \%)$, $49(38.9 \%)$ and $84(66.7 \%)$ were in age group of $40-49$, Christians by religion, Doctorate degree holders and married respectively.

\section{Knowledge of HCT among participants $N=126$.}

There were seven knowledge items in the questionnaire with 'No' and 'Yes' response. The knowledge of the participants were computed to give the mean score. Participants whose knowledge scores were equal to or above the mean value were considered knowledgeable while those who score below the mean score were considered not knowledgeable. Using this principle, 72(57.1\%) scored above or equal to the mean score while 54(42.8) scored below the mean score. Hence, it is deduced that $72(57 \%)$ of participants were knowledgeable while 54(42.8\%) were not knowledgeable. (Table 4.)

Table 2 showed that majority, 70(55.6) of participants knew that HIV testing goes along side with counseling. 81(64.3\%) have heard about HCT and 66(52.4\%) believed that HCT was important only to those who have been exposed to the risk factors. Only 44(34.9\%) participants knew that HCT can assist those who test positive to find solution to their health problems while $70(55.6 \%)$ participants knew that HCT assists uninfected persons to remain healthy.

\section{Association between demographic variables and knowledge of HCT.}

Table 4 showed that at $\chi^{2} \quad(p$-value $)$ of $23.05(<0.001)$ there is statistically significant association between gender and knowledge of HCT. There is also a significant association between marital status and Knowledge of HCT $\left(\chi^{2}=0.58\right.$, P-value $\left.<0.001\right)$. From the above data, it can be deduced that marriage is a major reasons why individuals for HCT. Findings from this study also showed that age group of 40-49 years had the highest level of knowledge regarding HCT. 


\section{Acceptance of HCT among participants (N=126).}

The questionnaire also contained HCT acceptance questions to elicit participants acceptance of HCT with 'No' and 'Yes' response. After assigning ' 1 ' and ' 0 ' to acceptance and non-acceptance respectively depending on the response of participants. A mean was calculated and used to categorize participants' level of acceptance of HCT.

Table 5 shows that $89(70.6 \%)$ scored above or equal to the mean acceptance score, majority of which are females $63(60 \%)$ were females. From table 3, majority (76\%) of participants have gone for HCT before, $77(61.1 \%)$ are still interested to go for HCT even if they have had it in the past, $85(67 \%)$ will encourage others to go for HCT. Similar study conducted among students of Addis Ababa University revealed that $47.2 \%$ of participants had gone for HCT while $80 \%$ have willingness to take HCT service ${ }^{[21]}$. Findings from this study showed that majority of the participants revealed that they cannot go for HCT in centers that are within or near to their neighborhood. This means that fear of stigmatization affects the acceptance of HCT.

\section{Association between demographic variable and knowledge with Acceptance of HCT among participants}

Table 5 showed that at $\chi^{2} \quad(\mathrm{P}$-value) of $23.038(<0.001)$ acceptance was observed to be more in participants who were knowledgeable of HCT. Hence, there is a significant association between Knowledge of HCT and its acceptance. Findings also revealed in Table 5 that at $\chi^{2}$ (P-value) of $11.939(<0.001)$ the gender of participants showed a high association with the acceptance of HCT. Females were observed to have high HCT acceptance than males. Marital status was also seen to have a significant association with the acceptance of HCT $\left(\chi^{2}=2.315\right.$, P-value $\left.<0.001\right)$

\section{Discusion}

Findings of this study revealed that participants had an overall knowledge of HCT. This is similar to the level of knowledge found among university students in North West Ethiopia ${ }^{[4]}$ and North Uganda ${ }^{[21]}$. Despite an increased level of knowledge among participants, majority did not know that HCT assist individuals who test HIV positive to find solution to their health problems. The significant increase in knowledge observed among participants could be because the study was conducted in an academic environment.

Evaluation of the association between the demographic variables and knowledge of HCT showed that females were more knowledgeable than males. This is in agreement with the result of the study carried out in Shanghai China ${ }^{[16][19][22]}$ but this was not synonymous with the findings of study conducted in Kwara state of Nigeria ${ }^{[10]}$.

The acceptance of HCT was high among participants which is similar to the result of studies conducted in other regions in Africa ${ }^{[12][14][17]}$ and Ethiopia ${ }^{[4]}$. Result from this study showed that high acceptance HCT was seen among female. Majority of participants feel that the site and location of HCT centers also matters. They expressed that they would not go for HCT in centers within or near to their neighborhood. Which is different from findings of similar studies conducted in Nigeria ${ }^{[12]}$ which identified proximity of HCT centers as a factor that facilitates the uptake of HCT. Participants who had knowledge of HCT showed high acceptance of it. Findings showed that there is a strong association between knowledge of HCT and its acceptance. This implies that knowledge affects the uptake of HCT. This is in line with the result of similar studies carried out in Northern Nigeria ${ }^{[10][15]}$. There is therefore the need to create a wider coverage of awareness so that individuals who have never gone for HCT will make up their minds to do so. Factors inhibiting the uptake and acceptance of HCT should also be identified and clarified. Men have been identified to have lower knowledge and acceptance, therefore, they should be targeted for proper awareness.

Though findings revealed a high level of knowledge and acceptance, there is much need to educate the few who do not know about it and who have not gone for it before. This will eventually bring about an increase in the knowledge and acceptance of HCT. Awareness about the importance of HCT should bring about knowledge about the importance of HCT. This is a major finding which revealed that despite high knowledge demonstrated by participants, majority did not know the usefulness and relevance of HCT.

\section{Recommendations}

From the findings of this study, it is therefore recommended that nurses and other health professionals have a very vital role to play in disemminating the information regarding HCT. Information should be conveyed to everybody through mass media and public education so that individuals can really have the knowledge about the importance of HCT and the role it plays in the prevention, treatment and control of HIV/AIDS. It was also noticed that women are likely to have more knowledge and acceptance of HCT than men, hence the need to really focus on men to raise their awareness and acceptance of HCT. 


\section{Conclusion}

This study was conducted to examine the knowledge and acceptance of HCT among staff of a private University in South west Nigeria. HCT was identified as a key strategy in the prevention, treatment and control of HIV/AIDS, thus the acceptance should be promoted through proper education and awareness. From the findings of this study, knowledge of HCT was observed to be an important factor that has a significant influence on the acceptance and uptake of HCT.

TABLES.

Tables 1. On demographic characteristics of participants $N=126$, Mean age $=42.6(S D \pm 0.9)$

\begin{tabular}{c|l}
\hline Variables & Frequency $(\%)$ \\
\hline Mender & $49(38.9)$ \\
Female & $77(61.1)$ \\
\hline Age & $14(11.1)$ \\
$30-29$ & $31(24.6)$ \\
$40-49$ & $62(49.2)$ \\
$50-59$ & $16(12.7)$ \\
$60-69$ & $3(2.4)$ \\
\hline Religion & \\
Christian & $118(93.7)$ \\
Muslim & $8(6.3)$ \\
\hline Education & $11(8.7)$ \\
Diploma & $36(28.6)$ \\
Bachelor degree & $30(23.8)$ \\
Master degree & $49(38.9)$ \\
Doctorate & $42(33.3)$ \\
\hline Marital status & $\mathbf{8 4}(66.7)$ \\
Unmarried &
\end{tabular}

Table 2 Knowledge about HCT N=126

\begin{tabular}{|c|c|}
\hline Questions & Frequency (\%) \\
\hline Have you heard about HCT before? & $\begin{array}{l}45(35.7) \\
81(64.3)\end{array}$ \\
\hline $\begin{array}{c}\text { Do you know HIV Testing is done with counseling? } \\
\text { No } \\
\text { Yes }\end{array}$ & $\begin{array}{l}49(38.9) \\
77(61.1)\end{array}$ \\
\hline $\begin{array}{l}\text { Is HCT important in the prevention, control and treatment of } \\
\text { HIV/AIDS? } \\
\text { No } \\
\text { Yes }\end{array}$ & $\begin{array}{l}74(58.7) \\
52(41.3)\end{array}$ \\
\hline $\begin{array}{l}\text { Is HCT important only for those who have been exposed to risk } \\
\text { factors? } \\
\text { No } \\
\text { Yes }\end{array}$ & $\begin{array}{l}66(52.4) \\
60(47.6)\end{array}$ \\
\hline $\begin{array}{r}\text { Do you know HIV testing is done voluntarily } \\
\text { No } \\
\text { Yes } \\
\end{array}$ & $\begin{array}{l}56(44.4) \\
70(55.6) \\
\end{array}$ \\
\hline $\begin{array}{l}\text { HCT assist infected individuals to seek solutions to their health } \\
\text { problems } \\
\text { No } \\
\text { Yes }\end{array}$ & $\begin{array}{l}82(65.1) \\
44(34.9)\end{array}$ \\
\hline $\begin{array}{c}\text { HCT helps those who are not infected to remain healthy } \\
\text { No } \\
\text { Yes }\end{array}$ & $\begin{array}{l}56(44.4) \\
70(55.6)\end{array}$ \\
\hline
\end{tabular}




\begin{tabular}{|c|c|}
\hline Table 3 on Acceptance of HCT & $\mathrm{N}=126$ \\
\hline Acceptance & Frequency (\%) \\
\hline Have you ever gone for HCT before & $\begin{array}{l}50(39.7) \\
76(60.3)\end{array}$ \\
\hline $\begin{array}{r}\begin{array}{r}\text { Do you have the interest to go for HCT even if you have had i } \\
\text { No } \\
\text { Yes }\end{array}\end{array}$ & $\begin{array}{l}49(38.9) \\
77(61.1)\end{array}$ \\
\hline Do you encourage others to go for HCT? & $\begin{array}{l}41(32.5) \\
85(67.5)\end{array}$ \\
\hline $\begin{array}{r}\text { Can you go for HIV testing in HCT centers within or near yo } \\
\text { No } \\
\text { Yes }\end{array}$ & $\begin{array}{l}87(69) \\
39(31)\end{array}$ \\
\hline
\end{tabular}

Table 4 on association between demographic variables and Knowledge $\quad \mathrm{N}=126$

\begin{tabular}{|c|c|c|c|}
\hline Variables & Not knowledgeable & Knowledgeable & $\mathrm{X}^{2}$ (P-Value \\
\hline $\begin{array}{l}\text { Gender } \\
\text { Male } \\
\text { female }\end{array}$ & $\begin{array}{l}34(27) \\
20(15.8)\end{array}$ & $\begin{array}{l}15(12.0) \\
57(45.2)\end{array}$ & $23.045(<0.001)$ \\
\hline $\begin{array}{l}\text { Age } \\
20-19 \\
30-39 \\
40-49 \\
50-59 \\
60-69 \\
\end{array}$ & $\begin{array}{l}9(7.1) \\
7(5.6) \\
30(23.8) \\
6(4.8) \\
2(1.6)\end{array}$ & $\begin{array}{l}5(3.9) \\
24(19) \\
32(25.3) \\
10(7.9) \\
1(0.8)\end{array}$ & $9.455,(0.077)$ \\
\hline $\begin{array}{l}\text { Religion } \\
\text { Christian } \\
\text { muslim }\end{array}$ & $\begin{array}{l}52(41.2) \\
2(1.6)\end{array}$ & $\begin{array}{l}66(52.3) \\
6(4.8)\end{array}$ & $1.112(0.178)$ \\
\hline $\begin{array}{l}\text { Education } \\
\text { Diploma } \\
\text { Bachelor } \\
\text { Master } \\
\text { doctorate } \\
\end{array}$ & $\begin{array}{l}9(7.1) \\
5(3.9) \\
15(12.0) \\
25(19.8)\end{array}$ & $\begin{array}{l}2(1.6) \\
31(24.6) \\
15(12.0) \\
24(19)\end{array}$ & 21.112(0.042) \\
\hline $\begin{array}{l}\text { Marital status } \\
\text { Unmarried } \\
\text { married }\end{array}$ & $\begin{array}{l}20(15.9) \\
20(15.8)\end{array}$ & $\begin{array}{l}22(17.5) \\
64(50.8)\end{array}$ & $0.583(<0.001)$ \\
\hline
\end{tabular}

Table 5 on association between demographic variables and Knowledge with Acceptance. $N=126$

\begin{tabular}{|c|c|c|c|}
\hline Variables & Non Acceptance & Acceptance & $\mathrm{X}^{2}$ (P-Value \\
\hline $\begin{array}{l}\text { Gender } \\
\text { Male } \\
\text { female }\end{array}$ & $\begin{array}{l}23(18.2) \\
14(11.1)\end{array}$ & $\begin{array}{l}26(20.6) \\
63(50)\end{array}$ & $\begin{array}{l}11.939 \\
(<0.001)\end{array}$ \\
\hline 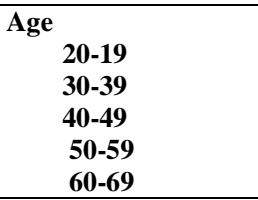 & $\begin{array}{l}9(7.1) \\
4(3.2) \\
22(17.5) \\
1(0.8) \\
1(0.8) \\
\end{array}$ & $\begin{array}{l}5(3.9) \\
27(21.4) \\
40(31.7) \\
15(11.9) \\
2(5.6)\end{array}$ & $\begin{array}{l}17.544 \\
(0.019)\end{array}$ \\
\hline $\begin{array}{l}\text { Religion } \\
\text { Christian } \\
\text { muslim } \\
\end{array}$ & $\begin{array}{l}36(28.6) \\
1(0.8)\end{array}$ & $\begin{array}{l}82(65) \\
7(4.8)\end{array}$ & $1.171(0.203)$ \\
\hline $\begin{array}{c}\text { Education } \\
\text { Diploma } \\
\text { Bachelor } \\
\text { Master } \\
\text { doctorate }\end{array}$ & $\begin{array}{l}9(7.1) \\
5(3.9) \\
10(7.9) \\
13(10.3)\end{array}$ & $\begin{array}{l}2(1.6) \\
31(24.6) \\
20(15.8) \\
36(28.6)\end{array}$ & $\begin{array}{l}21.112 \\
(0.042)\end{array}$ \\
\hline $\begin{array}{l}\text { Marital status } \\
\text { Unmarried } \\
\text { married } \\
\end{array}$ & $\begin{array}{l}20(15.9) \\
20(15.8)\end{array}$ & $\begin{array}{l}22(17.5) \\
64(50.8)\end{array}$ & $2.315(0.052)$ \\
\hline $\begin{array}{l}\text { Knowledge } \\
\text { Not knowledgeable } \\
\text { Knowledgeable }\end{array}$ & $\begin{array}{l}28(22.2) \\
9(7.1)\end{array}$ & $\begin{array}{l}26(20.6) \\
63(50)\end{array}$ & $\begin{array}{l}23.038 \\
(<0.001)\end{array}$ \\
\hline
\end{tabular}




\section{Competing interests}

We do not have any competing interests to declare

\section{Acknowledgements}

We are very grateful to all the participants in this study and also to the management of Babcock University. We also appreciate Dr (Mrs) Ojewole, Prof. E.Ajao, Mrs Ahuchauba and Miss T. Adebiyi for their kind support during the course of this study.

\section{References}

[1]. WHO: Global HIV/AIDS response: epidemic update and health sector progress towards universal access, progress report; 2011. http://www.unaids.org/en/media/unaids/contentassets/documents/unaidspublication/2011/20111130 ua report en.pdf.

[2]. Federal republic of Nigeria (2012) Global AIDS response: country progress report, Nigeria

[3]. UNAIDS (2012) Global report Annexes

[4]. Addis Z, Yalew A, Shiferaw Y, Alemu A, Birham W, Mathewose B \& Tachebele B. Knowledge, attitude and practice towards voluntary counseling and testing among university students in North West Ethiopia: a cross sectional study: BMC public Health 2013, 13: 714

[5]. Bernett T \& Whiteside A. AIDS in the $21^{\text {st }}$ century. Disease and globalization. New York, Palgrave, Macmillan, $2012:$ 3-23.

[6]. Caldwell J. Rethinking the African AIDS epidemic. Popul Dev Rev, 2012: 26(1): 117-135.

[7]. Ajakaiye D. Socio-economic of HIV/AIDS epidemic in Nigerian, Ibadan. Nigerian Institute of social and economic research, 2002: 23-25.

[8]. Admass M, Fitawi Y: Factors affecting acceptance of VCT among different professional and community groups in North and South Gonder administration zone, North West Ethiopia. Ethiop J health Dev 2006: 20: 24-31

[9]. Adedeji O.A, Olaleye A Suswam P. Role of volunteer in inproving access to HIV couseling and testing in Nigeria. Presented at the $6^{\text {th }}$ conference of International AIDS Society (IAS) July 2011 at Rome, Italy

[10]. Yahaya LA, Jimoh AAG \& Balogun OR. Factors in the rate of acceptance of HIV/AIDS voluntary counseling and Testing (VCT) among youths in Kwara State, Nigeria. Research Journal of medical sciences 20104 (3) 152-156

[11]. The World Bank (2008) Nigeria HIV/AIDS program development Project II. Accessed $13^{\text {th }}$ September, 2012

[12]. Olabode A: The sociodemographic and psychosocial determinant of HIV Voluntary counseling and testing among Nigerian University students. Dissertation: retrieved from http://www.udini.proquest.com/view/the-sociodemographic-and-goid:807419038.

[13]. Zubairu I, Isa S.A. Mohammed Kabir and Muktar H.A: Knowledge of HIV/AIDS and attitude towards voluntary counseling among adults JNati Med Assoc 2006, 98(12): 1917-1922.

[14]. Otasowale E.D. The knowledge and perception of HIV voluntary counselling and testing among young adults in Kempton Park community, North of South Africa. African Journal of Primary health care \& Family medicine 2010. Retrieved from http://www.phcfm.org/index.php/phcfm/thesis/view/50

[15]. Iliyasu Z, Abubakar IS, Kabir M \& Aliyu MH. Knowledge of HIV/AIDS and attitude towards voluntary counseling and testing among adults. J Nati Med Assoc. 2006: 98(12): 1917-22

[16]. Mungrue K, Sahadool S, Evans R, Boochay S, Ragoobar F, Maharaj K, Green S, Pennerman T \& Tayopa O. Assessing the HIV rapid test in the fight against the HIV/AIDS epidemic in Trinidad. HIV AIDS (Auckl). 2013 7; 5: 191-8.

[17]. Oppong AK \& Oti-Boadi M. HIV/AIDS knowledge among undergraduate university students: implications for health education programs in Ghana. Afr Health Sci. 2013; 13(2): 270-7

[18]. Mukolo A, Blevins M, Victor B, Paulin HN, Vaz LM, Sidat M \& Vergara AE. Community Stigma endorsement and voluntary counseling and testing behavior and attitude among female and heads of household in Zambezia province, Mozambique. BMC Public Health. 2013; 10;13:1155.

[19]. Jurgensen M, Sandoy IF, Michelo C, Fylkesnes K, Mwangala S \& Blystad S. The seven Cs of the high acceptability of home-based VCT: results from a mixed method approach in Zambia. Soc Sci Med. 2013; 97:210-9

[20]. Lau JT, Gu J, Tsui HY \& Wang Z. Prevalence and associated factors of intentions to participate in HIV voluntary counseling and testing for the first time among men who have sex with men in Hong Kong, China. Prev Med. 2013; 57(6):813-8

[21]. Regassa N, Kedir S. Attitude and practice on HIV preventions among students of higher education institutions in Ethiopia: the case of Addis Ababa Univerisity. East Afri J Public Health. 2011 June;8(2):141-54

[22]. Charles PM, Kweka JE, Mahande MA, Barongo RL, Shekalaghe S, Nkya MH, Lowassa A, Mahande JM: Evaluation of uptake and attitude to voluntary counseling and testing among health care professional students in Kilimanjaro region, Tanzania. BMC Public Health 2009, 9:128. 